\title{
Social and asocial cues about new food: Cue reliability influences intake in rats
}

\author{
GWEN DEWAR \\ University of Michigan, Ann Arbor, Michigan
}

\begin{abstract}
Dietary generalists often treat new foods with caution and may rely on social cues to identify new foods that are safe to eat. However, not all generalists show the same degree of caution, nor do they all rely on social cues to the same extent. The cue reliability approach (CRA) attempts to account for this variation by quantifying the costs and benefits of sampling a new food for the first time. The experiments reported here tested predictions of the CRA, and the results suggested that rats eat more new food when asocial cues predict that new foods will prove more profitable than familiar foods. The experimental results also suggested that rats are more likely to seek out social cues when asocial cues are unreliable.
\end{abstract}

Dietary generalists often treat new foods with caution, rejecting some new foods and eating others only in small quantities (Freeland \& Janzen, 1974; Galef \& Beck, 1990). However, generalists may overcome their neophobia if they encounter evidence that a new food has been eaten by conspecifics (Galef \& Beck, 1990; Galef \& Giraldeau, 2001). Researchers have interpreted these behaviors as strategies to reduce the risk of self-poisoning (e.g., Freeland \& Janzen, 1974; Rozin, 1976). Nonetheless, variation among generalists is not yet well understood. For instance, generalist species do not all show the same degree of caution when they evaluate new foods (Zahorik \& Houpt, 1981). Nor do all generalists rely on social cues to the same extent (e.g., Fragaszy \& Visalberghi, 1996; Galef, 1996). It seems likely that these behavioral differences reflect variations in the costs and benefits of sampling new food. If so, economic models may help researchers investigate the function of neophobia and food-related social cues.

One such economic model derives from the cue reliability approach (CRA), an application of expected utility theory and Bayesian principles (Dewar, 2003a, 2003b). According to the model, a forager should reject a new food item unless the probability that it is associated with a positive reward exceeds a minimum threshold. This reliability threshold is determined by the expected payoffs (aver-

This research was supported by grants from the Rackham Graduate School and the Department of Anthropology at the University of Michigan, Ann Arbor. I thank the support staff of ULAM for husbandry assistance; Seema Bhatnagar for the donation of pilot study subjects; Steffi Jesseau, Misty McPhee, and Bette Stallman for their technical advice; Iowa Limestone Company (Des Moines, IA) for the donation of calcium carbonate; Jim Vollmers and Adrienne Young for the loan of equipment; and Marguerite Flower, A. Roberto Frisancho, Jeff Galef, Bobbi Low, John Mitani, Susan Perry, and an anonymous reviewer for their comments on the manuscript. I am also especially grateful to Jeff Galef for his extensive technical guidance and editorial feedback. Correspondence should be addressed to G. Dewar, Department of Behavioral Sciences, Santa Rosa Junior College, Santa Rosa, CA 95401-4395(e-mail: gdewar@umich.edu). age gains or losses in fitness) associated with three actions: (1) eating a new item that has a positive payoff, (2) eating a new item that has a zero or negative payoff, and (3) rejecting a new item and seeking out familiar food instead. In particular, foragers should reject an unfamiliar food item unless the probability that it will yield a positive payoff exceeds $(F+B) /(G+B)$, where $F$ is the expected payoff for seeking out a familiar food, $G$ is the expected payoff for eating a good or safe new food with a positive payoff, and $-B$ is the expected payoff for eating a bad new food with a zero or negative payoff (see Appendix A). For example, suppose that $G$, the payoff for eating the average good new food, is twice as large as $F$, the payoff for seeking out familiar food. Assume also that $G$ is twice as large as the absolute value of $-B$, the payoff for eating bad new food. In such a case, the reliability threshold is $(1+1) /(2+1)$, or .667. Foragers should reject a new food unless it is good with a probability exceeding .67 .

The reliability threshold may vary if the expected payoffs vary. For instance, if familiar food is highly profitable and easy to find, the payoff for seeking out familiar food is high and the reliability threshold increases. Conversely, if the payoff for seeking out familiar food is low relative to the payoff for eating safe new food, the reliability threshold drops. The reliability threshold may also vary for different food categories. To illustrate, suppose that fungi are more frequently poisonous than are fruit and that the expected payoff for eating a safe new type of fruit is higher than the expected payoff for eating a safe new type of fungus. If these assumptions are true, the reliability threshold for new fruit types is lower than the reliability threshold for new fungus types. Moreover, reliability thresholds may depend on the characteristics of the forager, such as its capacity to detoxify poisons (Dewar, 2003a, 2003b). However, the same principle applies in all cases: When the payoff for seeking familiar foods is high relative to other payoffs, foragers should require more confidence that a new food is good or safe. 
How do foragers judge the probability that a new food is safe? Foragers do so by attending to social and asocial cues. Suppose, for instance, that the forager encounters an unknown type of bitter fruit. The forager can estimate $P_{\text {safe }}$, the probability that the food type has a positive payoff, by gauging the frequency of bitter fruits that are safe to eat. If, hypothetically, a forager knows that $50 \%$ of all bitter fruits are safe to eat, $P_{\text {safe }}=.50$. If .50 exceeds the threshold, the forager would be justified in sampling the new fruit. Otherwise, the forager should reject it. Either way, the forager uses a cue (bitter fruitiness) to judge the probability that the food is safe to eat. Although this scenario focuses on an asocial cue, social cues may also provide information about new food (see Appendix B). For example, food odors on the breath of a conspecific convey information about the probability that a particular food is safe. From the perspective of the CRA, the crucial attribute of a cue is not its social or asocial origins but its reliability. A cue is reliable if and only if it indicates that a new food has a positive payoff with a probability that exceeds the reliability threshold.

To apply the CRA to real animals, researchers must understand two points. First, the CRA does not imply that foragers make conscious calculations about payoffs, reliability thresholds, or probabilities. Like other functional models, the CRA assumes that animals behave as if they calculate costs and benefits. The CRA does not stipulate what mechanisms foragers use to identify cues or evaluate cue reliability. Foragers may learn about cues and reliability thresholds through direct experience (e.g., trial and error). Foragers may also be equipped with unlearned, prewired biases - for instance, a preference for sweet flavors-that help them identify reliable cues. Second, note that cue reliability is relative. A cue associated with a high probability of safety is not necessarily reliable, nor is a cue associated with a low probability of safety necessarily unreliable. The reliability threshold determines whether or not $P_{\text {safe }}$ is high enough to render cues reliable, and the reliability threshold depends on the relative profitabilities of eating new food and seeking out familiar food.

In the experiments reported here, I tested two hypotheses generated by the CRA model. According to the first, the local threshold hypothesis, foragers should trust cues about new foods as a function of the local reliability threshold. This hypothesis predicts that foragers should eat more new food in environments in which cues indicate that $P_{\text {safe }}$ exceeds the local reliability threshold. The second, social cue dependency, hypothesis concerns social cues. Numerous studies have indicated that foragers show a special attraction to new food marked by social cues (Galef \& Giraldeau, 2001). When subjects are offered a choice between two different types of new food-one type marked with social cues and the other type associated only with asocial cues-subjects often eat more of the socially marked type (Galef \& Giraldeau, 2001). This preference makes sense if social cues are reliable and asocial cues are not. In such cases, foragers should eat only socially marked food. The preference also makes sense if asocial cues are reli- able but are associated with lower probabilities of safety than are social cues. However, foragers should not necessarily pay exclusive attention to new foods marked by social cues. According to the social cue dependency hypothesis, foragers should reduce their dependence on reliable social cues when asocial cues are reliable. If asocial cues are reliable, foragers should be willing to sample new, unmarked food types, especially if foragers must work to find socially marked alternatives. The social cue dependency hypothesis predicts that foragers should eat more unmarked new food when asocial cues are reliable.

\section{EXPERIMENT 1}

In this experiment, I presented naive rats (Rattus norvegicus) with an experimental food category and information about the reliability threshold. All the subjects encountered a series of 12 differently flavored, encapsulated food types, 10 of which had a positive caloric value. Therefore, the probability that an encapsulated food was good or safe was $10 / 12$ or .83 for all the subjects. However, the subjects experienced different reliability thresholds, depending on group assignment. For the subjects in the high-threshold group, the average caloric density of safe encapsulated foods was low, which resulted in a reliability threshold exceeding 1.0. For the subjects in the low-threshold group, the average caloric density of safe encapsulated foods was high, yielding a reliability threshold below .6. Thus, asocial cues were unreliable for the high-threshold group $(.83<1.0)$ and were reliable for the low-threshold group $(.83>.6)$. Because rats can assess the caloric density of new foods they have eaten (Hayward, 1983; Melcer \& Alberts, 1989), I expected them to learn their assigned reliability thresholds. After exposure to all 12 food types, the subjects encountered a simultaneous choice between a familiar and a new food. I predicted that low-threshold subjects would eat more of the new food type than would highthreshold subjects.

\section{Method}

\section{Subjects}

Thirty-two experimentally naive, female Sprague-Dawley rats acquired from Harlan Labs (Indianapolis, IN) served as subjects. They were 29 days old at the beginning of the experiment.

\section{Housing}

During the 3 weeks of experimentation, I housed the subjects in the same groups of four each night in acrylic boxes measuring $43 \times$ $20.5 \times 18 \mathrm{~cm}$. During daytime training and testing, I removed the rats from group housing and housed them individually in box cages that measured $25.5 \times 15 \times 12.5 \mathrm{~cm}$.

\section{Base Diets}

I used four experimental base diets to make flavored foods. These diets were designed to be similar in texture, apparent fat content, sweetness, and saltiness. I prepared the diets in a manner similar to that of Galef (personal communication, June 2002) and Melcer and Alberts (1989) by mixing varying proportions of canola oil, Crisco, mineral oil, petroleum jelly, Polycose (Ross Laboratories, Columbus, $\mathrm{OH})$, cellulose, calcium carbonate, table salt, and saccharine. 
The resulting mixtures yielded (1) a high-calorie base diet of $6.8 \mathrm{cal} / \mathrm{g}$, (2) a moderate-calorie diet of $3.1 \mathrm{cal} / \mathrm{g}$, (3) a low-calorie base diet of $1.1 \mathrm{cal} / \mathrm{g}$, and (4) a noncaloric diet composed entirely of noncaloric elements (see Table 1)

\section{Flavor Additives and Encapsulation}

Before the base diets were fed to the subjects, I adulterated each mixture with one of 15 different flavors (Spice Islands' ground anise, cardamom, cinnamon, clove, cocoa, ginger, mace, marjoram, onion powder, paprika, and thyme; Bumble Bee's canned tuna; Marie's blue cheese dressing; McCormick's pure almond extract; and Realemon's lemon juice). The flavor agents accounted for approximately $1 \%$ of the weight of each flavored diet. Next, I injected the flavored pastes into cellulose capsules (Frontier Natural Products Co-op, Norway, IA). Each empty capsule weighed $0.1 \mathrm{~g}$. When it was filled, the average cellulose capsule weighed approximately $0.75 \mathrm{~g}$. The capsules were odor permeable so that subjects could smell the contents before opening them.

\section{Manipulation of the Reliability Thresholds}

To establish experimental reliability thresholds, I manipulated the payoffs for eating familiar, bad, and good or safe encapsulated foods (see Appendix A). I made familiar food from the moderate calorie $\operatorname{diet}(3.1 \mathrm{cal} / \mathrm{g})$ and flavored it with marjoram. Next, I made a series of bad new food types from the noncaloric diet, each type characterized by a different flavor. Finally, I made a series of safe new food types, each characterized by a different flavor, using the low-calorie $(1.1-\mathrm{cal} / \mathrm{g})$, moderate calorie $(3.1-\mathrm{cal} / \mathrm{g})$, and high-calorie $(6.8-\mathrm{cal} / \mathrm{g})$ diets. Over the course of the experiment, the high-threshold subjects encountered six food types made from the low calorie diet and four

Table 1

Composition (by Weight) of Base Diets

\begin{tabular}{lr}
\hline \multicolumn{1}{c}{ Component High-Calorie Diet $(6.8 \mathrm{cal} / \mathrm{g})$} & \\
\multicolumn{1}{c}{ Percentage of Mixture } \\
Canola oil & 39.1 \\
Crisco & 26.7 \\
Polycose & 19.0 \\
Calcium carbonate & 12.7 \\
Salt & 1.5 \\
Saccharine & 1.0 \\
\multicolumn{1}{c}{ Moderate-Calorie Diet $(3.1 \mathrm{cal} / \mathrm{g})$} & \\
Mineral oil & 30.5 \\
Canola oil & 7.6 \\
Petroleum jelly & 8.4 \\
Crisco & 18.3 \\
Polycose & 19.0 \\
Calcium carbonate & 13.7 \\
Salt & 1.5 \\
Saccharine & 1.0 \\
& \\
Mineral oil Low-Calorie Diet $(1.1 \mathrm{cal} / \mathrm{g})$ & \\
Petroleum jelly & 39.1 \\
Crisco & 22.6 \\
Polycose & 4.1 \\
Calcium carbonate & 19.0 \\
Salt & 12.7 \\
Saccharine & 1.5 \\
& 1.0 \\
Mineral oil No-Calorie Diet $(0 \mathrm{cal} / \mathrm{g})$ & \\
Petroleum jelly & 39.1 \\
Cellulose & 26.7 \\
Calcium carbonate & 19.0 \\
Salt & 12.7 \\
Saccharine & 1.5 \\
\hline & 1.0 \\
\hline
\end{tabular}

food types (including the familiar marjoram type) made from the moderate calorie diet. Thus, the high-threshold subjects experienced a total of 10 different safe food types, and their average payoff for eating a safe encapsulated food was $[(3.1 \times 4)+(1.1 \times 6)] / 10$, or $1.9 \mathrm{cal} / \mathrm{g}$. If the average payoff is treated as the equivalent of the expected payoff for eating a new safe food, this yields a reliability threshold of $(F+B) /(G+B)=(3.1+0) /(1.9+0)=1.63$. In contrast, the low-threshold subjects encountered six food types made from the high-calorie diet and four food types made from the moderate-calorie diet. Their average payoff for eating a safe food was $[(3.1 \times 4)+(6.8 \times 6) / 10]$, or $5.3 \mathrm{cal} / \mathrm{g}$, which yields a threshold of $(3.1+0) /(5.3+0)=0.59$.

\section{Procedure}

Experiment 1 was performed in two stages, a training stage and a test stage.

Training. The subjects were housed each night in groups of 4 . To control for possible cage effects, I assigned half of the subjects in each cage to the high-threshold treatment and the other half to the low-threshold treatment. The training for Experiment 1 proceeded in a series of eight cycles, with a 4-day break from training occurring between Cycles 4 and 5. Each cycle involved four steps, as described below.

Step 1, food deprivation. To ensure that the rats would eat new foods, I deprived the subjects of food for $14 \mathrm{~h}$ before beginning each daytime training session.

Step 2, training session. I removed the subjects from group housing and placed them in individual cages. Next, I gave each subject four capsules (weighing approximately $3 \mathrm{~g}$ total) of a new, distinctively flavored food type. This feeding occurred simultaneously for all the subjects, and all the subjects encountered foods of the same flavor. However, the caloric value of the foods fed to different subjects varied. The food fed to low-threshold subjects had a caloric density of either $6.8 \mathrm{cal} / \mathrm{g}$ or $0 \mathrm{cal} / \mathrm{g}$. The food fed to high-threshold subjects had a caloric density of either $1.1 \mathrm{cal} / \mathrm{g}$ or $0 \mathrm{cal} / \mathrm{g}$. To give the subjects time to digest and assess the caloric density of the new food type, I left them alone in individual housing for $1 \mathrm{~h}$.

Step 3, posttraining session feeding. After $1 \mathrm{~h}$, I permitted the subjects to feed ad lib on their regular maintenance diet (Purina Rodent Laboratory Chow 5001). To ensure that social cues did not influence learning, I left the subjects in their individual cages for another $5 \mathrm{~h}$ (Galef \& Kennett, 1985).

Step 4, return to group housing. I returned the subjects to group housing and allowed them to feed ad lib on their familiar rat chow. I also presented them with capsules of the familiar marjoram-flavored food. After 24-28 h, I repeated Steps 1-4, using a differently flavored food type, until the subjects had consumed a total of eight different new food types. For all the subjects, six of the food types consumed were caloric and two were noncaloric.

Additional food types. During the 4-day hiatus between Cycles 4 and 5, I presented the subjects with three additional new food types made from the $3.1-\mathrm{cal} / \mathrm{g}$ base diet. I presented these additional food types in the context of training the subjects for Experiment 2 (see below).

Order of presentation of food types. The presentation of new food types can be grouped into three phases. In the first phase, the subjects were presented with a series of four new food types. In the second phase, which occurred during the 4-day training hiatus, the subjects were presented with three new food types. In the third phase, the subjects were presented with four more new food types. This pattern can be represented as XXXX-XXX-XXXX. The order of presentation of caloric $(\mathrm{C})$ versus noncaloric $(\mathrm{N})$ food types was varied across subjects, so that an equal number of subjects experienced each of four orders: NCCC-CCC-NCCC, CNCC-CCC$\mathrm{CNCC}, \mathrm{CCNC}-\mathrm{CCC}-\mathrm{CCNC}, \mathrm{CCCN}-\mathrm{CCC}-\mathrm{CCCN}$.

Testing. After the subjects had completed the training, I kept them in group housing for one night, where they fed ad lib on fa- 
miliar rat chow. Next, I removed each subject from group housing and placed it in the same temporary, individual housing as that used for training sessions. Each subject received preweighed quantities of two different food types (approximately $3 \mathrm{~g}$ of each type) for $15 \mathrm{~min}$. For all the subjects, one food type was the familiar, marjoramflavored, $3.1-\mathrm{cal} / \mathrm{g}$ food. The other food type was also $3.1 \mathrm{cal} / \mathrm{g}$ but was flavored with mace, a flavor new to all subjects. After $15 \mathrm{~min}, \mathrm{I}$ removed each subject from individual housing and weighed the unconsumed amounts of each food type that remained. I calculated the total weight of each food type consumed.

Rationale for testing parameters. I limited each test to $15 \mathrm{~min}$ because the experiment was designed to test responses to a new food before the subjects were given an opportunity for postingestive evaluation of food. In addition, I gave the subjects $3 \mathrm{~g}$ of each food type because prior experience indicated that subjects given this amount could feed for 15 min without running out of food. It was important that the subjects be able to eat one food type exclusively without running out, since running out would make a subject's subsequent eating of the alternative type difficult to interpret (see below).

\section{Results and Discussion}

Four subjects ran out of one food type before the end of the 15-min interval, which makes their additional consumption of the alternative food type difficult to interpret (i.e., it is possible that these subjects ate the alternative food merely because they were not satiated after having run out of their preferred food). Thus, these 4 subjects were excluded from analysis. For the remaining 28 subjects, the primary results are summarized in Figure 1. As was predicted, the subjects in the high-threshold group ate significantly less new food than did the subjects in the lowthreshold group (Wilcoxon rank sum test, $N_{1}=13, N_{2}=$ $\left.15, W_{\mathrm{s}}=144, p=.023\right)$. Thus, the rats altered their willingness to eat new food in response to feedback obtained from previous encounters with other new foods.

Although the results support the prediction of the local threshold hypothesis, some cautionary notes are in order.

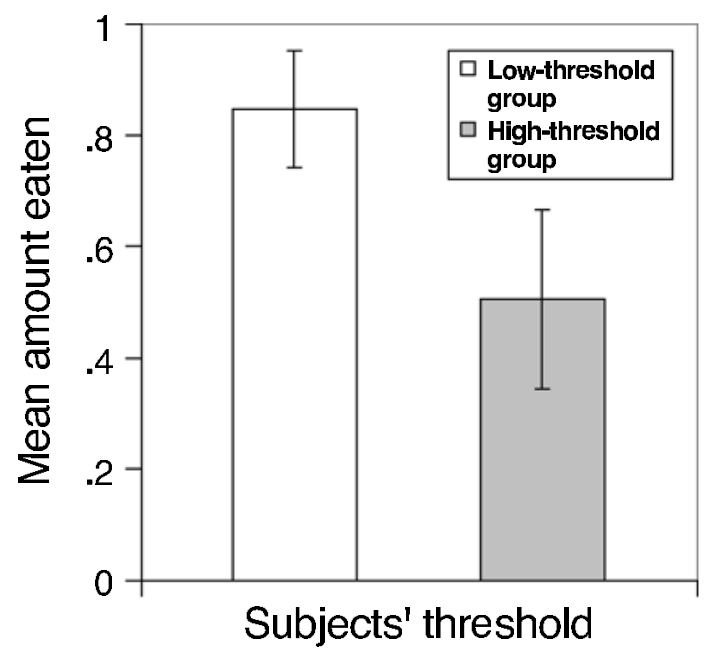

Figure 1. Experiment 1. The mean amount of new food eaten by low-threshold and high-threshold subjects during a 15-min food choice test. Low-threshold subjects: $M \pm S E M=0.846 \pm 0.106 \mathrm{~g}$. High-threshold subjects: $M \pm S E M=0.506 \pm 0.161 \mathrm{~g}$. Wilcoxon rank sum test, $N_{1}=13, N_{2}=15, W s=144, p=.023$.
First, the difference between treatment groups, although statistically significant, was not large. Second, the lowthreshold subjects did not prefer new food. For the lowthreshold subjects, the average ratio of new food eaten to familiar food eaten was 3:7, or 30\%. Although this ratio is higher than that of the high-threshold subjects, which was $2: 8$, or $19 \%$ (Wilcoxon rank sum test, $N_{1}=13, N_{2}=$ $\left.15, W_{\mathrm{s}}=145, p=.025\right)$, it falls short of a preference for new food. Third, most high-threshold subjects failed to show a strong aversion toward new food.

It is unclear why the observed difference was not larger. Possibly, 12 experiences with new food types were insufficient for some rats to learn the experimental thresholds. Rats may be equipped with prior notions about reliability thresholds, which would make it difficult to train them to learn arbitrary new ones.

\section{EXPERIMENT 2}

The results of Experiment 1 suggest that naive rats alter their intake of new foods in response to past experiences with other new foods. The purpose of Experiment 2 was to determine whether rats reduce their dependence on social cues when asocial cues are reliable. In some cases, social cues may be associated with a higher probability of safety than are asocial cues (Appendix B). If so, subjects should prefer new food types marked by social cues to new food types that are unmarked. However, even when socially marked food is safer, subjects should not necessarily ignore new food types that are socially unmarked. According to the social cue dependency hypothesis, subjects should increase their willingness to eat unmarked new food if two conditions hold true: (1) Asocial cues are reliable, and (2) socially marked new food is harder to obtain than is unmarked new food. The latter condition is important in cases in which socially marked food might be safer, since in such cases, subjects would have little incentive to eat unmarked food if safer, socially marked food were immediately available. I presented a subset of subjects from Experiment 1 (i.e., those that performed as if they recognized the experimental thresholds) with two new food types, one marked by social cues and the other unmarked. The socially marked food type was farther away and less abundant than the unmarked food type. On the basis of the CRA model, I predicted that low-threshold subjects would eat more unmarked new food than would high-threshold subjects.

\section{Method}

\section{Subjects}

Because the proposed test for Experiment 2 is valid only for subjects that have attended to experimental reliability thresholds, I excluded subjects that appeared to be poor learners in Experiment 1. For example, subjects trained to recognize a high reliability threshold should have rejected new food. Therefore, I excluded all members of the high-threshold treatment group that consumed more than $0.01 \mathrm{~g}$ of new food in Experiment 1. With the use of this criterion, I was left with 4 high-threshold subjects.

The definition of poor learners among the low-threshold subjects was more difficult. Given the predictions of the CRA, poor learners might be characterized as those who failed to prefer new food to fa- 
miliar food in Experiment 1. Unfortunately, by this criterion, virtually all the members of the low-threshold treatment group were poor learners. Although the low-threshold subjects ate more new food than did the high-threshold subjects, only 1 low-threshold subject ate more new food than familiar food. Therefore, I excluded subjects that ate less new food than the mean amount eaten by all low-threshold group members. This left me with 8 subjects, each of which consumed between 0.94 and $1.36 \mathrm{~g}$ of new food in Experiment 1.

In addition to these subjects, 8 female Sprague-Dawley rats served as demonstrators. These rats were the same age as the subjects.

\section{Housing}

The subjects were housed as in Experiment 1.

\section{Foods}

I continued to use the familiar marjoram-flavored food type that was described in Experiment 1. In addition, I introduced five new food types, all of which were made from the moderate, 3.1-cal $/ \mathrm{g}$ base diet that was described in the Method section of Experiment 1. Three of these new food types were used for training purposes. The remaining two were used for the test.

\section{Apparatus}

The testing apparatus was a maze-like box $(122 \times 61 \times 30.5 \mathrm{~cm})$ that consisted of two feeding chambers separated by a series of switchback passages that totaled $2.74 \mathrm{~m}$ in length (see Figure 2). In each feeding chamber, there was a demonstrator (housed in a wire mesh cage) and a quantity of new encapsulated food. In the social cue feeding chamber, there were two types of new food, each available in caches of approximately $2.25 \mathrm{~g}$. One food type had been recently fed to the demonstrator. This type was therefore marked by a social cue-that is, subjects could smell this food type on the demonstrator's breath. The other food type had not been eaten by the demonstrator and was thus unmarked. In the control feeding chamber, there was approximately $2.25 \mathrm{~g}$ of the unmarked food. The control demonstrator had not eaten any new food types and thus provided no social cues about food

In the apparatus as a whole, there was twice as much unmarked food as socially marked food. Thus, if a subject visited both chambers, two thirds of the food encountered would be unmarked. In addition, the subjects entered the apparatus at a point that was immediately adjacent to the control chamber and over $2.74 \mathrm{~m}$ away from the social cue chamber. As a result, obtaining socially marked food required more effort than obtaining unmarked food.

\section{Procedure}

The procedure consisted of two phases, a training phase and a test phase.

Training. I familiarized the subjects with the test apparatus by permitting them to explore it in a series of six sessions. Within each session, I left each subject in the apparatus until it had visited both chambers, sniffed each demonstrator, and investigated the available stashes of food. I permitted the subjects to eat freely from the food types available. The duration of each training session ranged from 5 to 30 min, depending on the speed with which each subject met the objectives of that session.

Testing. After a night of ad lib feeding on rodent chow, each subject spent $20 \mathrm{~min}$ in the test apparatus. Within each treatment group, half of the subjects experienced tuna-flavored food as the socially marked food and blue cheese-flavored food as the unmarked control food. The other half of the subjects experienced the converse. After $20 \mathrm{~min}$, I removed each subject from the apparatus and weighed the unconsumed amounts of each food type. I calculated the total weight of each food type that had been consumed.

\section{Results and Discussion}

As is shown in Figure 3, the subjects in the low-threshold group ate significantly more socially unmarked new food than did the subjects in the high-threshold group (Wilcoxon rank sum test, $\left.N_{1}=4, N_{2}=8, W_{\mathrm{s}}=12, p=.01\right)$. The results are therefore consistent with the hypothesis that foragers rely less on social cues when asocial cues are reliable and socially marked food is harder to obtain than is unmarked food.

\section{GENERAL DISCUSSION}

Previous research has shown that generalist foragers are often cautious about eating new foods. In addition, many generalists show a preference for new foods associated with social cues. Such findings seem consistent with the

$\begin{array}{ll}\begin{array}{l}\text { Control } \\ \text { chamber }\end{array} & \begin{array}{l}\text { Social cue } \\ \text { chamber }\end{array}\end{array}$

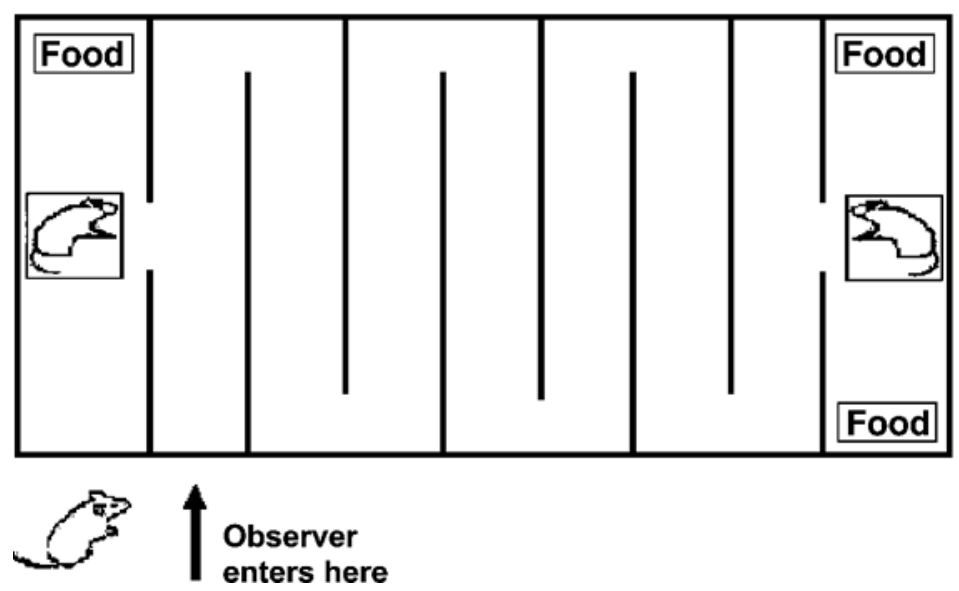

Figure 2. Overhead schematic drawing of the apparatus used in Experiment 2. 


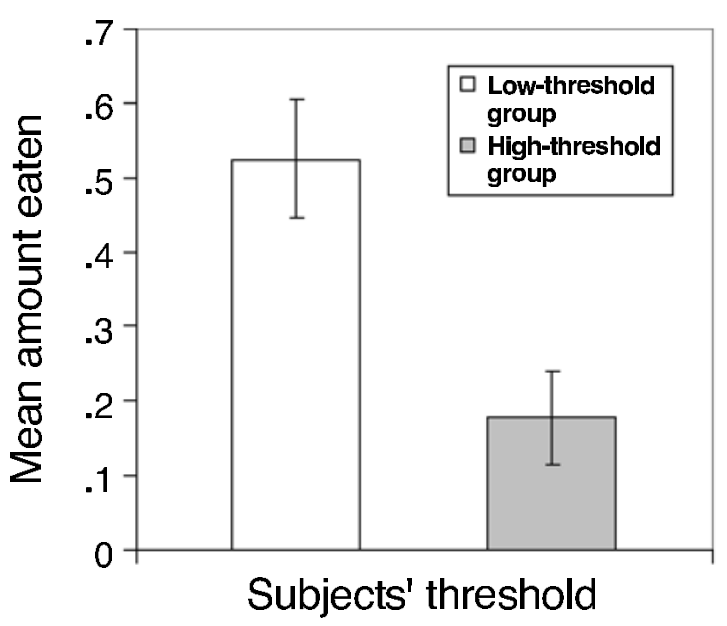

Figure 3. Experiment 2. The mean amount of socially unmarked new food eaten by subjects given the option to seek out socially marked new food. Low-threshold subjects: $M \pm S E M=0.525 \pm$ 0.08 g. High-threshold subjects: $M \pm S E M=0.178 \pm 0.063 \mathrm{~g}$. Wilcoxon rank sum test, $N_{1}=4, N_{2}=8, W \mathrm{~s}=12, p=.01$.

idea that neophobia and social learning are adaptive strategies to minimize the risk of ingesting poison. However, to evaluate the costs and benefits of such responses, a formal, quantitative model of the novel food encounter is needed. The CRA represents such a model. Cues provide foragers with information about the safety of new foods, but not all cues are equally trustworthy. Some cues may indicate that food is safe with a high probability; other cues may do so with a low probability. Whether or not the probability of safety is high enough to justify eating a new food depends on the local reliability threshold.

The experiments reported in this article represent the first test of the CRA model to novel food encounters. In Experiment 1, I presented subjects with a series of new food types and gave them information about the appropriate reliability threshold. As predicted, the subjects that encountered reliable asocial cues ate more new food than did the subjects that encountered unreliable asocial cues. In Experiment 2, the subjects had a choice between seeking out new food marked by reliable social cues and eating new food that was unmarked. In accord with the social cue dependency hypothesis, the subjects exposed to reliable asocial cues ate more unmarked food than did the subjects exposed to unreliable asocial cues. The results of both experiments indicate that rats can learn about experimentally imposed reliability thresholds. These results also suggest that rats take cue reliability into account when deciding whether to eat or reject new foods. Although rats may generally prefer familiar food or new foods marked by social cues, they do not necessarily ignore new food that is socially unmarked. In other words, the rats behaved as if food lacking social cues is still worth eating if asocial cues are reliable.
The results are important for understanding the role of social cues in populations of wild foragers. If asocial cues are reliable, foragers do not need social cues to learn what is safe to eat. Therefore, we cannot assume that shared dietary preferences always result from social learning. Suppose, for instance, that peanuts were eaten by only one rat population in the world, despite the wider availability of this food. Given such a pattern, we might be tempted to conclude that the preference for peanuts resulted from population-specific social transmission. However, it is possible that reliability thresholds vary across environments. Asocial cues could be reliable at one location and unreliable at others. If so, peanuts might be eaten at only one location because asocial cues are reliable only at this location. To identify bona fide food traditions, researchers will need to measure local reliability thresholds and determine the reliability of social and asocial cues (Dewar, 2003a). The case for a food tradition is strongly supported if social cues are the only reliable cues available. If, however, asocial cues are also reliable, more caution is warranted.

\section{REFERENCES}

DEWAR, G. (2003a). The cue-reliability approach to social transmission: Designing tests for adaptive traditions. In D. Fragaszy \& S. Perry (Eds.), The biology of traditions: Models and evidence (pp. 127-158). Cambridge: Cambridge University Press.

DEWAR, G. (2003b). Innovation and social transmission in animals: A costbenefit model of the predictive function of social and nonsocial cues. Unpublished doctoral dissertation, University of Michigan, Ann Arbor.

FraGASZY, D., \& ViSAlberGHi, E. (1996). Social learning in monkeys: Primate "primacy" reconsidered. In M. Heyes \& B. G. Galef, Jr. (Eds.), Social learning: The roots of culture (pp. 65-84). San Diego: Academic Press.

FreEland, W. J., \& Janzen, D. H. (1974). Strategies in herbivory by mammals: The role of plant secondary compounds. American Naturalist, 108, 269-289.

GALEF, B. G., JR. (1996). Social enhancement of food preferences in Norway rats: A brief review. In C. M. Heyes \& B. G. Galef, Jr. (Eds.), Social learning: The roots of culture (pp. 49-64). San Diego: Academic Press.

GALEF, B. G., JR., \& BECK, M. (1990). Diet selection and poison avoidance by mammals individually and in social groups. In E. M. Stricker (Ed.), Handbook of neurobiology: Vol. 10. Neurobiology of food intake and fluid intake (pp. 329-349). New York: Plenum.

GALEF, B. G., JR., \& GirAldEAU,L.-A. (2001). Social influences on foraging in vertebrates: Causal mechanisms and adaptive functions. Animal Behaviour, 61, 3-15.

GAlef, B. G., JR., \& KennetT, D. J. (1985). Delays after eating: Effects on transmission of diet preferences and aversions. Animal Learning \& Behavior, 13, 39-43.

HAYWARD, L. (1983). The role of oral and postingestional cues in the conditioning of taste preferences based on differing caloric density and caloric outcome in weanling and mature rats. Animal Learning \& Behavior, 11, 325-331.

Melcer, T., \& Alberts, J. (1989). Recognition of food by individual, food-naive, weaning rats (Rattus norvegicus). Journal of Comparative Psychology, 103, 243-251.

RozIN, P. (1976). The selection foods by rats, humans and other animals. Advances in the Study of Behavior, 6, 21-76.

ZAHORIK, D. M., \& HouPT, K. A. (1981). Species differences in feeding strategies, food hazards, and the ability to learn food aversions. In A. C. Kamil \& T. D. Sargent (Eds.), Foraging behavior: Ecological, ethological and psychological approaches (pp. 289-310). New York: Garland STPM Press. 


\section{APPENDIX A \\ How to Calculate the Reliability Threshold for \\ Heeding Social Cues About New Food}

When does it pay to eat a strange, new food? The answer depends on the following:

$+G=$ the expected (or average) payoff for eating a new item with a positive payoff,

$-B=$ the expected payoff for eating a new item a zero or negative payoff, and

$+F=$ the expected payoff for rejecting new food and seeking familiar food instead.

Given the probability $P$ that the new item has a positive payoff (i.e., that it is good or safe), the expected utility of eating the potential food item is

$$
(P)(G)+(1-P)(-B),
$$

and eating the item is more profitable than seeking out a familiar alternative when

$$
(P)(G)+(1-P)(-B)>F
$$

or

$$
P>(F+B) /(G+B) .
$$

In other words, a new item is worth eating if the probability that it is safe exceeds

$$
(F+B) /(G+B) .
$$

Thus, if one obtains estimates of the component payoffs $F, B$, and $G$, one can calculate the reliability threshold - that is, how confident foragers must be about the safety of a food type before they eat it for the first time. Reliability thresholds are situation specific, since the component payoffs may vary for different environments, food categories, and foragers. For example, the net payoff $F$ depends on how hard foragers must work to find and process familiar foods. $F$ is also diminished by predation risk-that is, how dangerousit is to forage for familiar foods. Likewise, the expected payoffs $G$ and $B$ vary on the basis of which category of new foods is selected, since some categories (e.g., nuts) are associated with higher nutritional rewards than are other categories (e.g., bark). Finally, these payoffs also vary according to a forager's ability to detoxify harmful ingested substances. In the research reported here, I manipulated the values of the component payoffs by creating a series of experimental food types. I simplified my calculations by eliminating (1) the work required to obtain familiar food and (2) predation risk. Payoffs were measured in caloric density, or calories per gram. 


\section{APPENDIX B}

\section{When are Social Cues Reliable?}

Suppose that an observer sees a demonstratoreating a new food type. This social cue is reliable when $T_{\text {obs }}$, the observer's threshold, is exceeded by $P\left(\mathrm{Obs}_{\mathrm{safe}} / \mathrm{Dem}_{\text {eats }}\right)$, the probability that a new food is safe for the observer given that the observer has seen the demonstrator eating it. $P\left(\mathrm{Obs}_{\mathrm{safe}} / \mathrm{Dem}_{\text {eats }}\right)$ can also be expressed as

$$
P\left(\mathrm{Obs}_{\mathrm{safe}} / \mathrm{Dem}_{\text {familiar }}\right) * P\left(\mathrm{Dem}_{\text {familiar }}\right)+P\left(\mathrm{Obs}_{\mathrm{safe}} / \mathrm{Dem}_{\text {new }}\right) * P\left(\mathrm{Dem}_{\text {new }}\right),
$$

where $P\left(\mathrm{Obs}_{\mathrm{safe}} / \mathrm{Dem}_{\text {familiar }}\right)$ represents the probability that the food is safe for the observer given that the food is familiar to the demonstrator, $P\left(\mathrm{Dem}_{\mathrm{familiar}}\right)$ represents the probability that the food is familiar to the demonstrator, $P\left(\mathrm{Obs}_{\text {safe }} / \mathrm{Dem}_{\text {new }}\right)$ represents the probability that the food is safe for the observer given that the food is new to the demonstrator, and $P\left(\mathrm{Dem}_{\text {new }}\right)$ represents the probability that the food is new to the demonstrator.

The first of these component probabilities, $P\left(\mathrm{Obs}_{\mathrm{safe}} / \mathrm{Dem}_{\text {familiar }}\right)$, depends on the demonstrator's relative tolerance to toxins. If the demonstrator is less tolerant (or as tolerant) as the observer, the demonstrator will avoid foods that are toxic to the observer. Postingestivefeedback inhibits demonstrators from repeating the ingestion of food types that induce illness or deliver only marginal rewards. Therefore, $P\left(\mathrm{Obs}_{\text {safe }} / \mathrm{Dem}_{\text {familiar }}\right)$ approaches 1.0, and the observer may safely sample from the demonstrator's familiar food repertoire. If, however, the demonstrator is more tolerant of toxins than is the observer, some food types in the demonstrator's repertoire might poison the observer. Social cue reliability would then depend on the observer's reliability threshold and the frequency with which the demonstrator ate such dangerous foods.

The probability of safety is also reduced if the demonstratorsamples new food. However, demonstrators should not sample new food unless they themselves are informed by reliable cues. This suggests a special case in which social cues are virtually always reliable. If, in addition to sharing similar tolerances, demonstrators and observers also share similar reliability thresholds, demonstrators should not eat new food unless the probability of safety exceeds $T_{\mathrm{obs}}$. Therefore, the lower boundary value for $P\left(\mathrm{Obs}_{\mathrm{safe}} /\right.$ Dem $\left._{\text {new }}\right)$ is $T_{\text {obs }}$, and

$$
P\left(\mathrm{Obs}_{\text {safe }} / \mathrm{Dem}_{\text {eats }}\right)>P\left(\mathrm{Dem}_{\text {familiar }}\right)+T_{\text {obs }} * P\left(\text { Dem }_{\text {new }}\right) .
$$

Because $P\left(\right.$ Dem $\left._{\text {familiar }}\right)$ and $P\left(\right.$ Dem $\left._{\text {new }}\right)$ are mutually exclusive events, $P\left(\right.$ Dem $\left._{\text {new }}\right)=$ $1-P\left(\mathrm{Dem}_{\text {familiar }}\right)$. Hence, $P\left(\mathrm{Obs}_{\text {safe }} / \mathrm{Dem}_{\text {eats }}\right)$ can be rewritten as $P\left(\mathrm{Dem}_{\text {familiar }}\right)+T_{\text {obs }}$ * $\left[1-P\left(\right.\right.$ Dem $\left.\left._{\text {familiar }}\right)\right]$, and $P\left(\mathrm{Obs}_{\mathrm{safe}} / \mathrm{Dem}_{\text {eats }}\right)$ exceeds the observer's threshold when

$$
P\left(\text { Dem }_{\text {familiar }}\right)+T_{\text {obs }} *\left[1-P\left(\text { Dem }_{\text {familiar }}\right)\right]>T_{\text {obs }},
$$

or

$$
P\left(\text { Dem }_{\text {familiar }}\right) / P\left(\text { Dem }_{\text {familiar }}\right)>T_{\text {obs }} .
$$

Thus, for reliability thresholds less than 1.0, some social cues are always reliable. In particular, social cues are reliable when demonstrators and observers share similar tolerances to toxins and are constrained by similar reliability thresholds. Such conditions are likely to arise when demonstrators and observers are (1) physiologicallysimilar (i.e., conspecifics of similar age, sex, body size, and condition) and (2) share roughly similar familiar food repertoires. In other words, we might expect familiar peers to be reliable demonstrators. Social cues are also reliable when demonstrators have higher reliability thresholds and greater vulnerability to toxins than do observers. When demonstratorsare more resistant to toxins and/or have lower reliability thresholds (because they are less familiar with local resources or have reduced access to familiar foods $), P\left(\mathrm{Obs}_{\text {safe }} / \mathrm{Dem}_{\text {eats }}\right)$ decreases. 